\title{
Business opportunities and challenges as the two sides of the climate change: Corporate responses and potential implications for big data management towards a low carbon society
}

\author{
Bruno Michel Roman Pais Seles ${ }^{a}$, Ana Beatriz Lopes de Sousa Jabbour ${ }^{\mathrm{b}}$, \\ Charbel José Chiappetta Jabbour ${ }^{\text {b, }}$, Paula de Camargo Fiorini ${ }^{\text {a, b}}$, Yusliza Mohd-Yusoff ${ }^{c}$, \\ Antônio Márcio Tavares Thomé ${ }^{\mathrm{d}}$ \\ a UNESP - Sao Paulo State University, Av. Eng. Luiz Edmundo C. Coube 14-01, Bauru, Sao Paulo 17033-360, Brazil \\ ${ }^{\mathrm{b}}$ Montpellier Business School, Montpellier Research in Management, 2300, avenue des Moulins, 34185, Montpellier, Cédex 4, France \\ c School of Maritime Business \& Management, Universiti Malaysia Terengganu, 21030 Kuala Nerus, Terengganu, Malaysia \\ d Industrial Engineering Department, Pontifical Catholic University of Rio de Janeiro, Rua Marquês de São Vicente, 225 sala: 952L, 22453-900, Rio de Janeiro \\ RJ, Brazil
}

\section{A R T I C L E I N F O}

\section{Article history:}

Received 16 December 2017

Received in revised form

13 March 2018

Accepted 12 April 2018

Available online 13 April 2018

\section{Keywords:}

Big data

Environmental management

Global warming

Climate change

Sustainable operations

\begin{abstract}
A B S T R A C T
Climate change represents a long-term risk to society, and this risk extends to organizations across several sectors. The risks associated with climate change have both pros and cons, and it is thus important to understand how organizations deal with the opportunities and challenges that climate change presents. Furthermore, big data has gained increasing prominence due to its potential to transform ways of doing business. It is therefore important to understand the implications which big data will have for managing corporate responses to the opportunities and challenges presented by climate change. In this context, this article aimed to identify and analyze the challenges and opportunities that the climate crisis presents for organizations and to understand how organizations respond to this scenario, while examining the implications of big data management. This work adopted a structured literature review research method. The review showed that the opportunities emerging from the climate crisis tend to improve performance (environmental, financial and operational) as well as generating new business, while the challenges are related to the lack, or inefficiency, of governmental and regulatory support and an increase in costs. It was also identified that organizations respond to the climate crisis by investing in research and development, as well as through cooperation with other organizations. The results of this research serve as a guide for organizations that are concerned with the climate crisis situation, but currently can neither face the challenges it presents nor realize that this apparently threatening scenario also holds great business potential. The article also contributes to the debate on climate change policy by means of shedding light on possible methods to encourage organizations to make short-term investments to deal with the contingencies presented by climate change. Finally, the article also highlights the effects of big data.
\end{abstract}

๑) 2018 Elsevier Ltd. All rights reserved.

\section{Introduction}

Climate change represents a huge, long-term risk to all societies

\footnotetext{
* Corresponding author.

E-mail addresses: bruno_seles@yahoo.com.br (B.M. Roman Pais Seles), a.sousajabbour@montpellier-bs.com (A.B. Lopes de Sousa Jabbour), cjcjabbour@gmail. com (C.J.C. Jabbour), paula.fiorini@feb.unesp.br (P. de Camargo Fiorini), yusliza@ umt.edu.my (Y. Mohd-Yusoff), mt@puc-rio.br (A.M. Tavares Thomé).
}

(World Business Council for Sustainable Development, 2004). For this reason, both societies and governments have been attempting to secure deals that will reduce the emission of 'greenhouse gases' worldwide.

The Paris Agreement was recently signed at the 21st Conference of the Parties (COP21). This agreement aims to maintain global warming below $2{ }^{\circ} \mathrm{C}$, limiting temperature increases to $1.5^{\circ} \mathrm{C}$ above pre-industrial levels (United Nations, 2015). The agreement requires a myriad of actions worldwide, and determines that 
developed countries must invest 100 billion dollars per annum in fighting climate change and supporting sustainability in developing countries (United Nations, 2015). However, the USA, ranked second in the world for greenhouse gas emissions, declined to sign the agreement, thus generating uncertainties regarding the future of global actions to mitigate climate change. The reasons cited for the American government's refusal to support the agreement were that the Paris Agreement was "unfair" and could put the USA economy at risk (British Broadcasting Corporation, 2017; The New York Times, 2017).

In this climate crisis scenario, the operations of organizations across several sectors have been put at risk (Bicknell and McManus, 2006; Jarvis and Ortega, 2010). Further sectors are indirectly affected through the pressure exerted by stakeholders (Sprengel and Busch, 2011; Böttcher and Müller, 2015) and the market (Lee et al., 2015), which monitor organizations' actions. As a consequence, organizations must either adapt to or focus on mitigating climate change. It has therefore been necessary for organizations to mobilize internally, adopting environmental management initiatives and low carbon operations management practices.

However, business opportunities are also created by the climate change situation, as the United Kingdom Environment Agency's report indicates (Environment Agency, 2015). The report identifies that, for every three risks highlighted by British organizations, there is at least one opportunity. Furthermore, 33\% of these opportunities are expected to materialize over the next three years.

Considering the facts outlined above, the importance of comprehending that the climate change situation can generate both opportunities and challenges for organizations is vital (Gasbarro et al., 2017). It is also crucial to understand how organizations respond to these opportunities and challenges, for example whether internal changes are necessary, and how they are established. The existing literature explores only fragments of this situation. Additionally, big data has gained increasing prominence due to its potential to transform ways of doing business (Berner et al., 2014; Chen and Zhang, 2014; Akter et al., 2016; Popovič et al., 2016). It is important to understand the implications that big data management will have for corporate responses to climate change. Moreover, information technologies with a green approach may have the capacity to influence total income and firm-level profits. For example, El-Kassar and Singh (2018) indicated that the successful implementation of some environmental practices depends on organizational effort and skill, which would include big data and predictive analytics.

What, then, are the challenges and opportunities that climate change presents to organizations? Furthermore, how do these organizations respond to this scenario?

This article aimed to explore the current literature regarding the opportunities and challenges created by climate change, identifying organizations' responses, and highlighting several research gaps which, if filled, would contribute to the overall knowledge and understanding of the topic. Finally, this paper also demonstrated the potential implications of big data management. Big data management is a key issue in the move towards a more sustainable society, as it can maximize the business opportunities resulting from climate change, while at the same time reducing the associated challenges (Song et al., 2017).

To achieve the proposed goals, a structured literature review was adopted, similar to those research methods employed by Lage Junior and Godinho Filho (2010), Jabbour (2013), Mariano et al. (2015) and Thomé et al. (2016) and examined in detail by Gaur and Kumar (2018).

The article is structured as follows. The next section presents the theoretical foundation for the climate crisis and environmental management, after which the research method is addressed. The results are reported and discussed in Section 4, with subsection 4.1 presenting a bibliometric analysis. Subsection 4.2 presents the dimensions considered in the analysis of the identified articles, including the opportunities and challenges arising from the climate crisis and how organizations respond to this scenario. Subsection 4.3 demonstrates the implications of managing the opportunities and challenges of corporate responses to climate change for big data management. Finally, Section 5 presents the conclusions of the study.

\section{Theoretical foundation}

\subsection{Climate crisis and environmental management}

According to the World Business Council for Sustainable Development (WBCSD) (2004), climate change represents a significant risk and appears as a long-term process. In this context, organizations from several sectors are either directly or indirectly impacted by global warming (Bicknell and McManus, 2006; Jarvis and Ortega, 2010).

Ski resorts, for example, are directly affected, as this sector's activities directly depend on a specific biome which is highly threatened by the increase in global temperature (Bicknell and McManus, 2006). Agribusiness is another sector directly affected by the climate crisis, as farming production is impaired by inclement weather, which has become more and more common (Organisation for Economic Co-Operation and Development, 2015).

Other sectors are indirectly affected, mainly due to the actions of stakeholders (Sprengel and Busch, 2011; Böttcher and Müller, 2015), such as regulatory and public pressure (Kolk and Levy, 2001), and market pressures (Lee et al., 2015), which demand that organizations focus on climate change mitigation and adaptation. This means that organizations must take part by implementing internal changes to face these challenges as well as to trying to take advantage of the opportunities that this context generates for their businesses. However, according to Jones and Levy (2007), it is important to note that organizations pursue different response strategies depending on their exposure to climate risks, their sector, their individual capabilities, and their leadership. Griffiths et al. (2007) show that the national governance system also helps shape industry and corporate activities in response to the challenges of greenhouse gas reduction, leading to variations in climate change approach between organizations. For example, these strategies may include formal and informal management control systems, as presented by Lueg and Radlach (2016) concerning the management of sustainable development within management control systems.

In this context, some organizations develop internal policies regarding climate change (Lee et al., 2015), such as investing in research and development to mitigate and adapt to the climate crisis (Lee et al., 2015; Kuo et al., 2015), adopting low-carbon operations management practices (Raar, 2015; Singh, 2015), controlling and disclosing the costs and benefits of their climate change mitigation actions (Lee, 2012; Schaltegger and Csutora, 2012) and cooperating with other organizations (Bicknell and McManus, 2006; Kuo et al., 2015).

For such internal changes to take place, internal environmental management can be an important starting point for organizations. Environmental management consists of many activities which aim to reduce organizations' processes and produce positive environmental outcomes. These help organizations to reach their environmental goals (Rao, 2002; Zhu and Sarkis, 2006), while directly and simultaneously maximizing the environmental, social and 
economic aspects of organizational performance (De Giovanni, 2012). Jarvis and Ortega (2010), in their investigation of hotels in Spain, found that many organizations in that sector have adopted environmental management strategies to tackle climate change issues.

The importance of putting internal environmental management into practice, as well as implementing organizational changes, has become clearer with the expanding literature and evidence. Agan et al. (2013), for instance, have shown that small and mediumsized organizations with ISO 14001 certification have better performance in environmental processes, such as those that mitigate the emission of greenhouse gases. Rankin et al. (2011) have shown that organizations with environmental management systems have a greater tendency to disclose their actions and beneficial effects regarding greenhouse gas mitigation. Therefore, environmental management can be an important path for organizations to adapt to the effects of climate change and to start mitigating greenhouse gas emissions.

The next section describes the research method adopted.

\section{Research method}

A structured literature review was employed as a research method, similar to those used in the work of Lage Junior and Godinho Filho (2010), Jabbour (2013), Mariano et al. (2015) and Thomé et al. (2016), with an in-depth examination presented by Gaur and Kumar (2018). The method is consistent with the application of systematic literature reviews in management (Tranfield et al., 2003) and with the detailed step-by-step approach advocated by Thomé et al. (2016) for operations management. The secondary data was content analyzed following the guidelines proposed by Seuring and Gold (2012).

The first stage of the research was to determine the research question and goals. From this the following stages were developed, as shown in Fig. 1.

Two searches of the Scopus database were carried out, using two different combinations of keywords. In the first search the following keyword combination was entered: ["environmental management" AND "climate change "] or ["environmental management" AND "global warming "] or [ "environmental management" AND "climate crisis"] and [firms] or [corporates]. In order to guarantee the efficiency of the search returns in answering the defined research question, the search was limited to certain document types. This was carried out using the search tools available in the Scopus database. The document types to which the search was limited included the following: article, review, and article in press. It must be emphasized that this first search was not limited by publication year or knowledge area. The second search used the following keyword combination: ["environmental management" AND "climate change "] or ["environmental management" AND "global warming "] or ["environmental management" AND "climate crisis"] and [organizations] or [organizations]. The second search of the Scopus database was limited by document type and knowledge area, but not by the publication year. The document types to which the search was limited were: article, review and article in press. Regarding knowledge areas, the following topics were excluded: Medicine, Biochemistry, Genetics and Molecular Biology, Chemistry, Immunology and Pharmacology.

The first search identified 98 articles. All of these were submitted to research filter 1 (RF1), which comprised the reading of article titles, abstracts and keywords. In order for articles be considered suitable according to RF1 they had to show potential to match the inclusion criterion (IC): articles which further understanding of the challenges and opportunities climate change

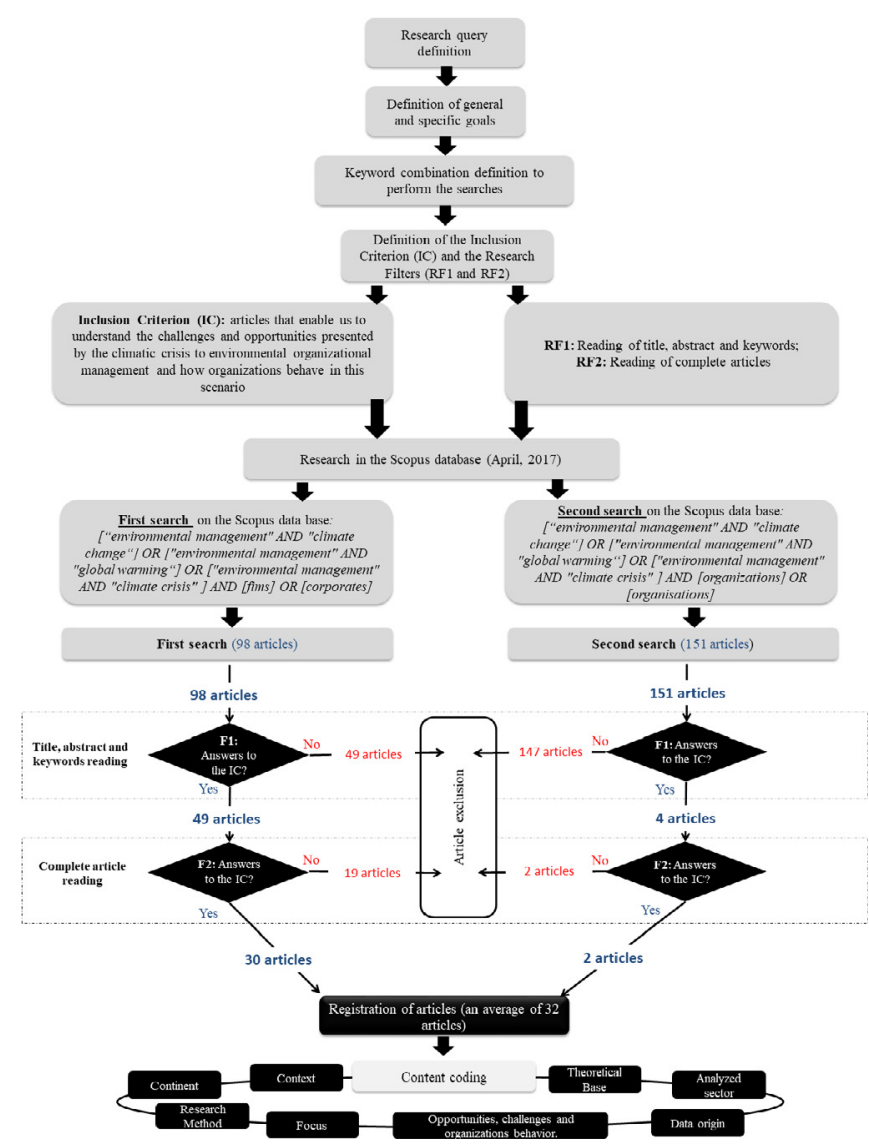

Fig. 1. Flowchart of the stages developed in the research

presents to organizations, and how organizations respond to this scenario. Of the 98 articles, only 49 were judged suitable. These 49 articles were submitted in sequence to research filter 2 (RF2) for a complete reading of the article. As with RF1, only the articles that met the IC moved on to RF2. From these 49 articles, 30 were approved at RF2 as they fully matched the IC. The same process was executed for the second search, where 151 articles were initially identified, with only 2 articles being approved at RF2. The reason for this low percentage of was that most of the articles identified during the first search also appeared during the second, and the duplicate articles were, therefore, not analyzed. Finally, from the results of both searches, 32 articles were found to fit the defined research question.

The content of these 32 articles was codified according to the dimensions shown in Chart 1 . As detailed by Gaur and Kumar (2018), coding is an important tool which highlights an article's success at analyzing its subject matter.

As shown in Chart 1, the 32 articles were classified into 8 dimensions: context, continent, theoretical base, research method, data origin, analyzed sector, focus, and opportunities, challenges and organizational response. All categories and codes presented in Chart 1 are derived from the research question and its goals.

In the "Context" dimension the articles were codified according to the economic context of the country in which the research was carried out. In this way, the context was classified as "A" (developed countries), "B" (developing countries), "C" (developed and developing countries) and " $\mathrm{D}$ " (not applicable). The "Context" coding " $\mathrm{D}$ " was given to articles that did not specify the country in which the research was conducted, or which were not related to country. The "Continent" dimension served to identify the global regions in 
which the research was conducted. Thus, each continent was represented by a code letter from " $\mathrm{A}$ " to "I", with " $\mathrm{H}$ " meaning "all continents" and "I" meaning "not applicable". The "theoretical base" dimension was established to verify whether or not articles developed their analysis based on a particular theory, in order to understand and interpret the research results. The article coding for this dimension was from "A" to "I", where "E" represented "not applicable or not specified". The "Research Method" dimension explored the methods used in the 32 articles (see Chart 1). The "Data origin" dimension examined whether the data used in the articles was secondary data or the result of empirical research. In the "Analyzed sector" dimension, the sectors explored by the articles were classified as "A" (manufacture), "B" (services), "C" (manufacture and services) and "D" (not applicable/not specified). The "Focus" dimension served to classify the articles according to their approach to the topic and its goals. Finally, the "Opportunities, challenges and organizational response" dimension was used to analyze the results of each article and to classify them according to their evidence. It also examined whether they presented evidence of climate crisis opportunities and challenges, and organizations' responses to this situation.

The articles' analysis by dimension, and their respective coding, enabled a broad thematic understanding, and in turn the proposition of research gaps within each of the dimensions analyzed.

\section{Research results \& discussion}

\subsection{Bibliometric analyses}

A timeline showing the evolution of published articles related to the challenges and opportunities presented to organizations by the climate crisis is shown in Fig. 2.

The first publication identified was from 2001. In that year, Takahashi et al. (2001) investigated the actions adopted by Canadian organizations to deal with the Kyoto Protocol. 2015 was identified as the year with the highest number of publications on the topic, with eleven publications in total.

Of the 32 identified articles, Reid and Toffel's article (2009) had the highest citation rate (see Table 1). Reid and Toffel (2009) examined the disclosure of organizational strategies within American organizations, in order to mitigate climate change in response to private and public policies. Table 1 lists the articles alongside their respective citation rates, according to the Scopus database.
Table 1

Citation rate of articles identified in the structured literature review

\begin{tabular}{|c|c|}
\hline Writers & Citation rate on Scopus \\
\hline Reid and Toffel (2009) & 143 \\
\hline Bicknell and McManus (2006) & 62 \\
\hline Revell et al. (2010) & 54 \\
\hline Sueyoshi and Goto (2010) & 48 \\
\hline Schaltegger and Csutora (2012) & 43 \\
\hline Rankin et al. (2011) & 37 \\
\hline Sprengel and Busch (2011) & 36 \\
\hline Martin et al. (2012) & 24 \\
\hline Lee $(2012)$ & 23 \\
\hline Agan et al. (2013) & 22 \\
\hline Harmes (2011) & 18 \\
\hline Dragomir (2012) & 15 \\
\hline Takahashi et al. (2001) & 15 \\
\hline Ziegler et al. (2011) & 13 \\
\hline Gallego-Álvarez et al. (2011) & 12 \\
\hline Kuo et al. (2010) & 12 \\
\hline Liu (2012) & 8 \\
\hline Lee et al. (2015) & 2 \\
\hline Wahyuni and Ratnatunga (2015) & 2 \\
\hline Albornoz et al. (2014) & 2 \\
\hline Gans and Hintermann (2013) & 2 \\
\hline Jabbour et al. (2015) & 2 \\
\hline Jarvis and Ortega (2010) & 2 \\
\hline Kuo et al. (2015) & 1 \\
\hline Yu et al. (2016) & 0 \\
\hline Walenta (2015) & 0 \\
\hline Raar (2015) & 0 \\
\hline Sugita and Takahashi (2015) & 0 \\
\hline Misani and Pogutz (2015) & 0 \\
\hline Demertzidis et al. (2015) & 0 \\
\hline Singh $(2015)$ & 0 \\
\hline Böttcher and Müller (2015) & 0 \\
\hline
\end{tabular}

\subsection{Dimension analyses}

The content of the articles presented in Table 1 were analyzed according to the dimensions cited in Chart 1 , and research gaps have been identified.

\subsubsection{Context and continent}

The majority of the identified articles (59.38\%) carried out their research in the context of developed countries (Fig. 3), with only $21.88 \%$ of the 32 articles exploring the impact of the climate crisis on organizations in developing countries. It was noted, however, that three of the articles focused their research on both developed and developing countries. These three articles were written by Sprengel and Busch (2011), Dragomir (2012) and Misani and Pogutz

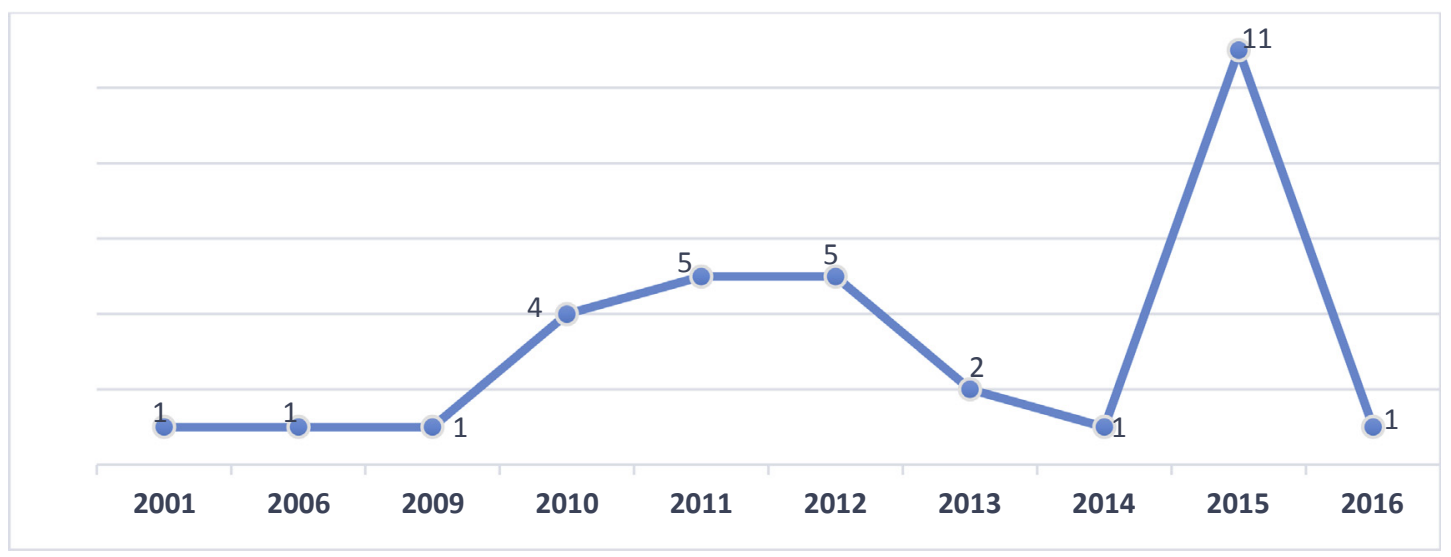

Fig. 2. The evolution of publications on the climate crisis and environmental management 


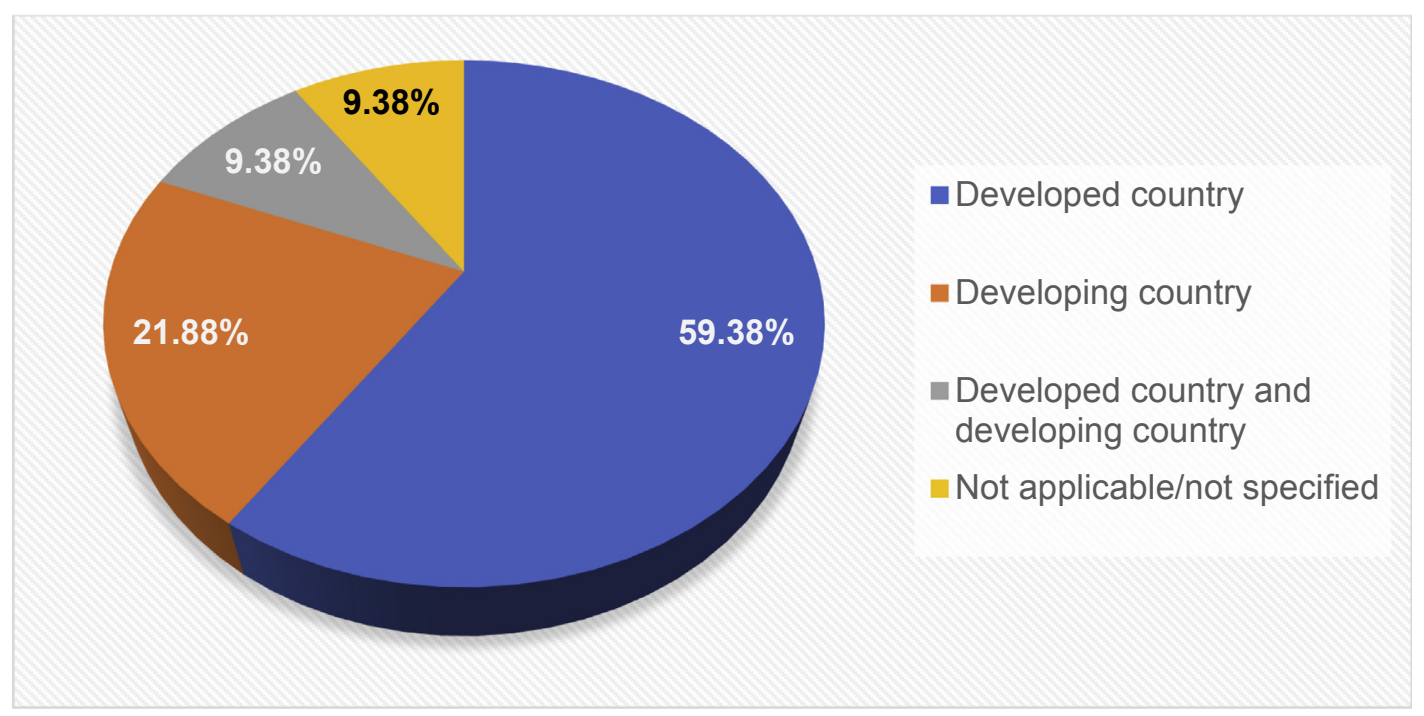

Fig. 3. Country context: the economic contexts investigated by the articles identified

(2015).

Asia was the most studied continent (see Table 2), followed by Europe and North America, respectively. Only Misani and Pogutz (2015) carried out research in countries on all continents. The most studied countries were Australia and Japan, which were both analyzed in 4 articles. The United States was examined in three articles, followed by China and the United Kingdom, which each appeared in two articles.

From this, the topic's first research gap (RG1) was determined:

- RG1: Investigating the challenges and opportunities presented by the climate crisis to organizations, and their responses to this scenario, in developing countries, especially those in Central America, Africa and South America. Developing countries tend to suffer more from the economic impacts of climate change and are also less adaptable to new climate conditions (McGuigan et al., 2002). In Latin America, for instance, national economies are totally dependent on hydric and natural resources, and with water shortages due to climate change increasing they have become more vulnerable, putting their economic growth and job generation at risk (Nações Unidas no Brasil, 2016). For these reasons, evaluating the responses of organizations in these countries to the climate crisis is of paramount importance.

\subsubsection{Theoretical bases, research method and data origin}

The majority of the articles examined ( 25 articles) did not use theories to underpin their analysis or discussions. Only seven articles adopted at least one theoretical base. Two articles used

Table 2

A breakdown of the continents examined in the articles identified

\begin{tabular}{ll}
\hline Continent & Quantity of articles \\
\hline North America & 6 \\
Central America & 1 \\
South America & 3 \\
Europe & 9 \\
Africa & 0 \\
Asia & 10 \\
Oceania & 4 \\
All continents & 1 \\
Not applicable & 1 \\
\hline
\end{tabular}

Stakeholders Theory, Raar (2015) and Sprengel and Busch (2011). Gallego-Álvarez et al. (2011) used Legitimacy Theory, Rankin et al. (2011) employed Institutional Governance System Theory, while Reid and Toffel (2009) based their discussion on Social Movement Theory. Only two articles adopted more than one theory: Kuo et al. (2015) combined Stakeholder Theory and Signaling Theory, while Wahyuni and Ratnatunga (2015) used both Contingency Theory and the Resource-Based View.

From this analysis, the second research gap (RG2) was identified:

- RG2: Investigating and analyzing the challenges and opportunities the climate crisis presents to organizations, and their responses to this situation, using theoretical lenses. Filling this gap is fundamental to the development of the field, and as these theories are important lenses of analysis for several areas, this will enable more in-depth discussion and debate (Glaser and Strauss, 2009).

In terms of the research methods employed by the articles, around $66 \%$ of the 32 articles adopted a quantitative research method, using many statistical techniques, such as Data Envelopment Analysis (DEA) and ANOVA. Only 34\% of the articles employed a qualitative approach, within which $18.75 \%$ carried out case studies and $6.25 \%$ performed reviews. None of the articles used mixed methods; for example, applying a case study and surveys to the same research. Of 32 articles, 15 used secondary data, 16 used empirical research and only one article used both secondary data and empirical research.

The third research gap (RG3) was therefore determined:

- RG3: Applying a mixed method approach to research that deals with the challenges and opportunities presented by the climate crisis to organizations and their responses to this situation. An approach using mixed methods enables a broader and deeper analysis of the object under study, integrating both quantitative and qualitative elements (Johnson et al., 2007; Tashakkori and Creswell, 2007).

\subsubsection{Analyzed sectors}

As shown in Table 3, sixteen of the identified articles (50\%) 
Table 3

Frequency distribution of the sectors investigated by the articles identified

\begin{tabular}{lll}
\hline Sectors studied & Absolute Frequency & Relative Frequency \\
\hline Manufacture & 16 & $50.00 \%$ \\
Services & 4 & $12.50 \%$ \\
Manufacture and Services & 9 & $28.13 \%$ \\
Not applicable/Not specified & 3 & $9.38 \%$ \\
Total & 32 & $100 \%$ \\
\hline
\end{tabular}

looked exclusively at the manufacturing sector, while only four solely studied the services sector. However, nine articles examined organizations from both the manufacturing and service industries.

However, most of the articles did not take into account that differences between these two sectors can affect the way the opportunities and challenges of the climate crisis appear to each sector, as well as the ways in which the organizations in each sector - considering each sector's particular characteristics - respond to the scenario. For this reason, the fourth research gap (RG4) was determined:

- RG4: Investigating how the opportunities and challenges created by the climate crisis differ between organizations in the manufacturing and services sectors and how the organizations in each sector respond to this situation. This research gap is proposed because the effect of greenhouse gas emissions differs across sectors (Intergovernmental Panel on Climate Change, 2007), as do governmental regulations aiming to mitigate climate change (Wahyuni and Ratnatunga, 2015).

\subsubsection{Focus}

This section discusses the focus of the articles. As can be seen in Table 4, the majority (17 articles) focused on investments, strategies and management practices related to low-carbon operations management. The second most popular angle was that of environmental performance. However, few articles approached the issue of regulatory and stakeholder pressure.

\subsubsection{Opportunities, challenges and organizational response}

Most of the articles dealt with the angles presented in Table 4 in specific ways, and their results show some of the challenges and opportunities that climate change can create at the organizational level, as well as how organizations respond or should respond within that context. Some of the evidence presented by the articles will be discussed in the analysis of the results.

Based on the analysis of the results from the 32 identified articles, it was determined that the challenges presented by the climate crisis at an organizational level, as found in the literature were: the lack or inefficiency of regulatory and governmental support; stakeholder pressure; market pressure; the inherent characteristics

Table 4

Focus of the articles identified

\begin{tabular}{ll}
\hline Focus & $\begin{array}{l}\text { Absolute } \\
\text { Frequency }\end{array}$ \\
\hline Environmental Performance & 11 \\
Operational and Financial Performance & 9 \\
Regulatory Pressure & 2 \\
Stakeholder Pressure & 4 \\
Investments, strategies and practices of environmental & 17 \\
$\quad$ management (applied to manage low-carbon operations) & \\
Climate change impact on businesses (Opportunities and & 7 \\
$\quad$ Challenges) & 8 \\
Organizational Characteristics (culture, department, size) & 8 \\
\hline
\end{tabular}

of each organization; the quality and efficiency of the actions and practices of low-carbon operations management and an increase in costs.

Lack or inefficiency of regulatory and governmental support: For Demertzidis et al. (2015), the most notable risk is the one caused by climate change regulations, which, according to the authors, focus only on reinforcing the regulator's regime so that they can consolidate business operations in an environmental context. Liu (2012) showed that the uncertainties of Chinese government policies have made it difficult for Chinese firms to choose among alternative strategies for addressing carbon management. Similarly, Yu et al. (2016) demonstrated that the lack or inefficiency of regulatory and governmental incentives can generate a large discrepancy in environmental performance across organizations in many sectors, leading to the existence of sectors with a high level of adopted practices and other sectors with few or almost no adopted environmental practices. Agan et al. (2013) have shown that governmental regulations alone are not effective in handling pollution and climate change. In their study of small and mediumsized organizations they identified that these organizations want their business partners' and governors' assistance, as well as regulations. This was confirmed by Jarvis and Ortega (2010), who identified that, although some hotels in Spain are employing environmental management strategies to handle climate change issues, these organizations lack local government support.

Stakeholder Pressure: Böttcher and Müller (2015) found that stakeholder pressure and competitive expectations push organizations towards adopting low-carbon operations. Sprengel and Busch (2011), analyzing four diverse groups of organizations using environmental strategies to tackle climate change issues, demonstrated that the three groups of stakeholders that exercise the most pressure are the government, NGOs (Non-Governmental Organizations) and the media. Meanwhile, managers do not distinguish between pressures from different stakeholders; they perceive only the overall pressure exerted on the organization.

Market Pressure: According to Lee et al. (2015), the market punishes organizations which are indifferent to the reduction of greenhouse effect gas emissions, and these undesirable market pressures, related to negative environmental performance, are more prevalent than good market reactions to a positive environmental performance.

Organizations' Characteristics: Some organizations' characteristics, such as sector, size, culture and structure, may represent challenges in a climate crisis context. Bicknell and Mcmanus (2006), for example, showed the direct problems that the climate crisis creates in certain sectors, such as the situation of ski resorts in Australia. Jarvis and Ortega (2010), showed that smaller organizations in defined sectors, such as small and medium-sized hotels in Spain, can face financial barriers due to the availability of resources. Another critical issue is the type of organizational culture which can influence climate change mitigation, as discussed by Sugita and Takahashi (2015). According to Sugita and Takahashi (2015), adaptive cultures have positive relationships with management systems, product development and the climate change mitigation aspects of environmental management. More conservative cultures have negative relationships with all these elements. Liu (2012) studied Chinese firms and discovered that the structure of the organization could represent a challenge in a climate crisis context. For example, when a hierarchical system inhibits flexibility and innovation and no incentives are built into the budgetary system, this decreases carbon innovation.

The quality and efficiency of low-carbon operation management actions and practices: Dragomir (2012) drew attention to the poor quality of sustainability reports, especially in relation to 
carbon emissions data. The author analyzed sustainability reports from the top five largest European oil and gas companies and identified reports containing unexplained figures and methodological inconsistencies on carbon emission data. For this reason, the quality of practices, such as data disclosure, is an important challenge organizations must face.

Increased costs: Another important challenge for organizations is the balance between cost and returns on adoption of low-carbon operation management practices and actions. As presented by Raar (2015), small and medium-sized organizations believe that global warming may have the potential to increase costs. This fact is emphasized by Lee et al. (2015), who state that incorporating environmental sustainability can create additional costs.

Focusing on the challenges presented by the climate crisis, the following research gaps require development:

- RG5: Investigating the ways in which organizations develop the internal capabilities to tackle the challenges presented by the climate crisis. Darnall and Edwards (2006) have shown that some capabilities are important in the adoption of environmental management systems, reducing the opportunities for organizations that do not have such capabilities.

- RG6: Investigating the quality and efficiency of low-carbon operations management practices adopted by organizations as a response to the possible pressures of the climate crisis. Dragomir (2012) discussed the inferior quality of sustainability reports, highlighting that what is disclosed does not reflect what it is really practiced by the organizations.

The opportunities identified from these articles can be classified as follows: improvement of environmental performance; improvement of financial performance; improvement of operational performance; improvement of relations with stakeholders; and new business opportunities.

Improvement of environmental performance: Lee et al (2015) highlighted that incorporating environmental sustainability into an organization's decisions can generate costs, but also offers environmental performance improvement.

Improvement of financial performance: Lee et al. (2015) also emphasized that the incorporation of sustainability into organizations' decisions can lead to an improvement of financial performance. According to Misani and Pogutz (2015), organizations achieve the highest financial performance at the intermediate level of carbon performance. The authors also claimed that environmental processes moderate this relationship as they reinforce firms' financial performance through improved stakeholder management. Moreover, according to Agan et al. (2013), waste and environmental management systems positively impact financial performance. Organizations that introduce and spread climate change mitigation initiatives, can benefit from increased financial returns, as a valorization of their actions (Gans and Hintermann (2013). Ziegler et al. (2011) found similar results in the American energy sector. Additionally, Walenta (2015), in an investigation of the effectiveness of carbon neutral certifications as a means to achieving economic and environmental benefits at a coffee cooperative in Costa Rica, showed that certification ensured the financial stability of coffee farmers that had taken part in the cooperative for four years. Nevertheless, Walenta (2015) argued that there is no definitive conclusion on the issue.

Improvement of operational performance: Martin et al (2012) showed that climate-friendly environmental management practices were associated with low energy intensity and high productivity.

Improvement of relations with the stakeholders: According to Misani and Pogutz (2015), management of stakeholder relations is improved by adopting global warming mitigation practices. As shown by Lee et al. (2015), organizations displaying a "believable commitment", measured by investment in environmental technology, create a positive reaction in the market. Raar (2015) highlighted that the adoption of environmental practices creates changes in occupational health and security, decreases organizations' concerns related to their employment contracts with collaborators, and supports a safe working environment which attracts new talent. With regards to the customers' perspective, Raar (2015) emphasized that global warming can influence the redesign of organizations' projects as well as their relationships with customers, while also increasing marketing opportunities.

New business opportunities: For Lee et al. (2015), climate change mitigation actions, such as research and development, can create new business opportunities, which, if competently explored, can further lead to improved environmental and financial performance. Revell et al. (2010) identified that manager-owners of small and medium-sized organizations believe that the benefits of forward thinking and strong action against climate change overcome the associated costs, and that the transition to a low-carbon economy will bring opportunities for business growth.

Considering the compiled literature, the following research gaps were identified:

- RG7: Investigating how the climate crisis can create new business opportunities for organizations and if, despite those opportunities, there might be a larger reason for organizations not to adopt climate change mitigation practices. Recently, the Environment Agency (2015) of the United Kingdom government issued a report demonstrating that local organizations identified opportunities in the climate crisis; for every three risks noted, one opportunity was also spotted. In addition, $33 \%$ of the identified opportunities are expected to materialize within the next three years.

- RG8: Investigating whether strategies, actions and practices to mitigate the climate crisis generate an improvement in organizations' operational performance, as discussed by Martin et al. (2012).

Having discussed the evidence for organizational responses to the challenges and opportunities created by the climate crisis scenario, it is important to highlight that different organizations' individual characteristics can influence their responses. For this reason, the topic "organizational characteristics dependency" was included to describe the ways in which the literature classifies and discusses organizational responses. Such responses include: voluntary adoption of low-carbon operations management practices; investment in research and development; control and disclosure of costs and benefits; the development of internal policies; and cooperation.

Organizational characteristics dependency: Organizational responses to challenges and opportunities depend on their characteristics. For example, Kuo et al. (2015) showed that state-owned organizations in China are pioneers in terms of implementing national global warming mitigation policies, and that private organizations practice comprehensive disclosure of their sustainable development strategies. Wahyuni and Ratnatunga (2015) found that organizations operating in the same industry employ different carbon strategies and carbon management practices due to carbon extensions, configurations and regulations specific to each sector, and the capacities of each organization to deal with issues related to carbon emissions. Albornoz et al. (2014) have shown that foreign organizations in Argentina implement more environmental actions than local organizations. The evidence shows that local organizations implement more environmental actions if they have both 
formal and informal connections with their consumers and if their suppliers are foreign. Foreign organizations adopt environmental strategies due to organizational policies or in order to prepare themselves for environmental certification (Albornoz et al., 2014). Jabbour et al. (2015) highlighted the relevance of the human aspect in making companies more environmentally friendly, and that environmental management requires the support of human resources.

Considering the organization of human resources, Martin et al. (2012) identified that organizations tend to adopt more environmental practices when climate change issues are managed by an energy or environmental manager, and if that manager is close to the organization's CEO. Agan et al. (2013) demonstrated that small and medium-sized organizations with ISO 14001 certification perform better at environmental processes. A similar result was found by Rankin et al. (2011), who showed that organizations which voluntarily disclose their actions regarding the mitigation of greenhouse gas emissions have better environmental management systems (independently of whether or not they are certified). In addition, organizations with better corporative governance tend to be larger and to display greater environmental impacts. This supports the view of Sueyoshi and Goto (2010), who posited that large Japanese manufacturing organizations have greater financial and technological capacities for environmental protection than smaller organizations. Lastly, Gallego-Álvarez et al. (2011) noted that organizations from the countries that ratified the Kyoto Protocol disclosed more information about the effect of greenhouse gas emissions at their sites, compared with organizations from the countries that have not ratified it.

Voluntary adoption of low-carbon operations management practices: According to Raar (2015), a voluntary approach to environmental management can increase profits. This helps to explain voluntary actions in sectors that are not known to generate vast quantities of greenhouse gases, such as the financial sector. According to Singh (2015), even financial institutions need to adopt environmental practices due to climate change, despite the fact that their actions do not have direct environmental impacts. Thus, banks should adopt environmental practices in their operations, installations, investment and financing strategies (Singh, 2015).

Investment in research and development: Lee et al. (2015) showed that environmental research and development are fundamental to organizational environmental commitment. Furthermore, Lee et al. (2015) state that regulations and agreements, such as the Kyoto Protocol, can boost investments in environmental research and development, which will contribute to improved financial performance. Kuo et al. (2015) highlighted that for Chinese organizations to maintain their competitive advantage, managers must pay more attention to the research and development of environmental management techniques.

Control and disclosure of costs and benefits: Lee et al. (2015) highlighted that, in order to benefit from improved financial and environmental performance, organizations need to measure and report the costs and benefits of global warming mitigation. Ecocontrol, as Lee (2012) points out, can maintain the alignment between a low-carbon management strategy and carbon performance measurement, as well as providing useful information for organizations' decision makers. A similar point is made by Schaltegger and Csutora (2012) when detailing carbon accounting.

Internal policy development: According to Lee et al. (2015), institutional policies which are well designed to measure and report climate change can facilitate the development of organizations' technologies and capacities related to climate change.

Cooperation: Finally, the importance of cooperation must be highlighted. Bicknell and McManus (2006) emphasized that cooperation with other organizations strongly influences the types of response which organizations can develop. Kuo et al. (2015), in research conducted in China, stated that the sustainable development of a business in a competitive environment depends on environmental management techniques and maintaining a competitive advantage; managers need to seek cooperation from foreign organizations in the area of environmental management.

Considering the possible organizational responses to a climate crisis scenario as found in the literature, the following research gaps were noted:

- RG9: Investigating the relationships between the low-carbon practices adopted by organizations based on organizational characteristics (e.g. size, financial situation, culture, department and country), since the literature suggests that those characteristics can explain, to a certain extent, organizational responses to challenges and opportunities derived from the climate crisis (Sueyoshi and Goto, 2010; Gallego-Álvarez et al., 2011; Rankin et al., 2011; Agan et al., 2013; Albornoz et al., 2014; Kuo et al., 2015; Wahyuni and Ratnatunga, 2015).

- RG10: Investigating the types of low-carbon practices adopted by organizations as a result of cooperation with other organizations. The importance of international cooperation is highlighted by Philibert (2004) - in a work carried out by the Organization for Economic Co-operation and Development (OECD) and the International Energy Agency (IEA) - which confirms that the current globalization of investment, trade and innovation must be seen as an opportunity to accelerate the development and diffusion of climate-favorable technologies. Moreover, the author emphasized that international technological cooperation, through information, cost and effort sharing, can accelerate and facilitate technical change.

In conclusion, Fig. 4 summarizes the challenges and opportunities presented by the climate crisis, and organizational responses to this situation.

The implications of big data management for approaching the opportunities and challenges of corporate responses to climate change are presented below.

\subsection{Implications of big data management}

Big data has become a topic of great interest in information systems research (Agarwal and Dhar, 2014) as well as in other areas, such as logistics and supply chain management (Waller and Fawcett, 2013; Schoenherr and Speier-Pero, 2015; Dubey et al., 2015; Akhtar et al., 2016; Wang et al., 2016; Pan, 2017; Wu et al., 2017), and production and operations management (Belaud et al., 2014; Feng and Shanthikumar, 2017; Zhang et al., 2017); and has been seen as a revolution in business management (Erevelles et al., 2016; McAfee and Brynjolfsson, 2012). It has attracted enormous attention worldwide due to its huge potential to transform ways of doing business - including the possibility of creating competitive advantage (Matthias et al., 2017) - management and research (Akter et al., 2016; Berner et al., 2014; Chen and Zhang, 2014; Popovič et al., 2016).

The concept of big data is defined as the use of massive amounts of data to support different types of decision-making (Davenport, 2014; Goes, 2014). It is often characterized among scholars and practitioners by the notion of several "Vs". The big data "Vs" have evolved from the classical three - volume, variety, and velocity - to include two more recent additions: veracity and value (Fosso Wamba et al., 2015). Whereas volume and variety refer to the large quantity of several types of data from varied sources, velocity 


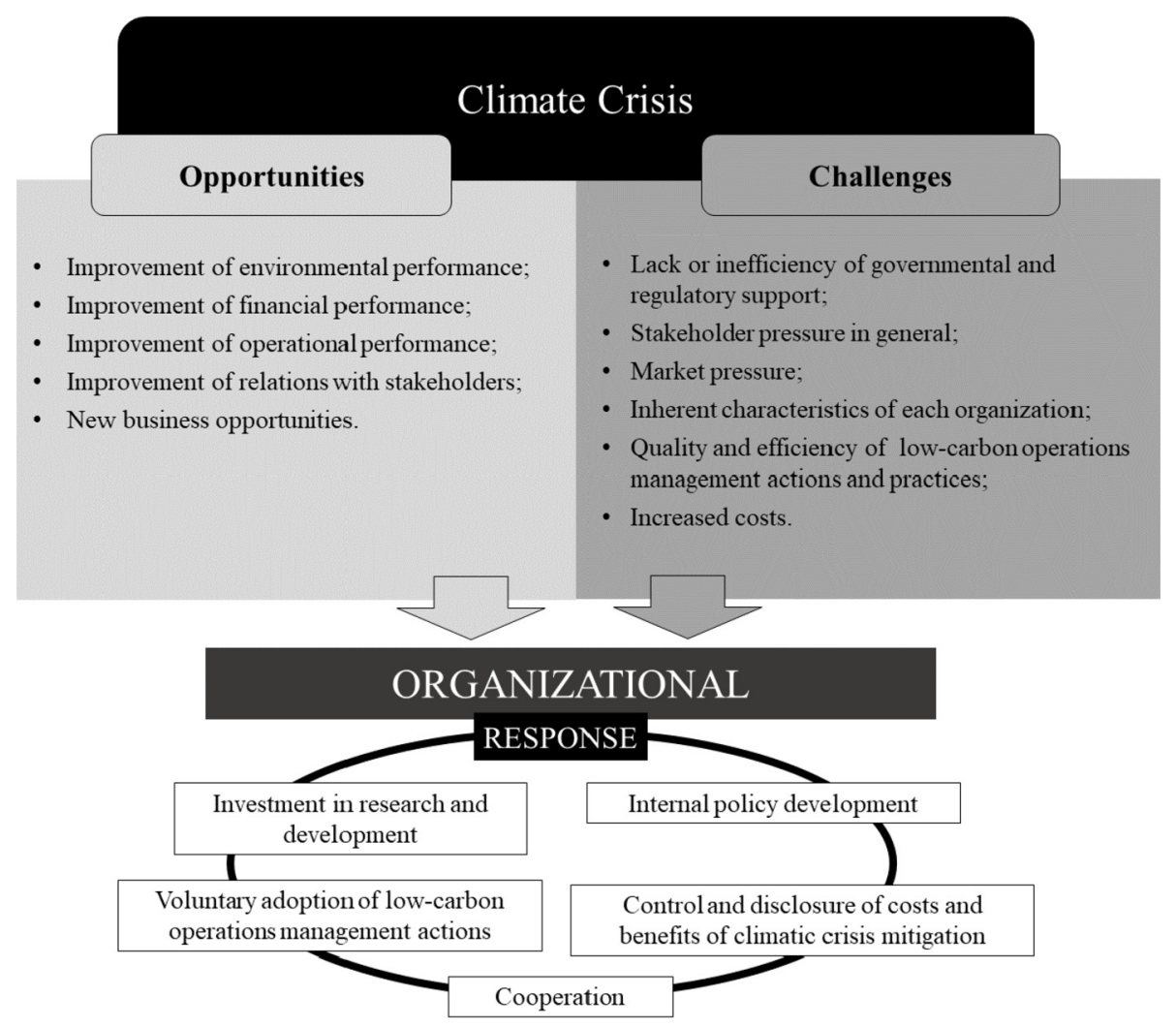

Fig. 4. Summary of challenges and opportunities of the climate crisis and organizational responses

refers to the rapid rate at which the data is generated (Dubey et al., 2017). Veracity, in turn, represents the unreliability inherent in some sources of data, which requires analysis in order to gain reliable predictions (Gandomi and Haider, 2015). Finally, value refers to the extent to which big data generates worthwhile insights and benefits through data analysis (Fosso Wamba et al., 2015).

It has been argued that big data management signifies a major opportunity in corporate sustainability, due to its potential to generate a better understanding of the opportunities and challenges of climate change. For example, Song et al. (2017) confirmed that the use of big data can directly affect the possibility of pursuing a more sustainable society. In addition, El-Kassar and Singh (2018) indicated that big data and predictive analytics may be important for the successful implementation of some environmental practices, such as green innovation.

In this research, the implications of big data for understanding corporate responses to climate change was considered as an emerging topic, a debate which is still in its infancy. However, based on Fig. 4, it is possible to suggest that big data management may have the following implications for managing the opportunities and challenges of corporate responses to climate change:

- Opportunities: big data management has been positively linked to better organizational performance. This may mean that, by adopting big data, companies will improve their ability to manage and track their environmental, economic and operational performance. Additionally, big data can unlock better corporate engagement with stakeholders and advance the discovery of new businesses avenues;

- Challenges: big data can also have major impacts in dealing with the challenges of managing climate change. If properly managed, big data can help governments to develop smart regulations that will boost proactive climate change responses from companies. The use of big data may also enhance firms' understanding of stakeholder pressures, market patterns, costs, and efficiency issues in terms of moving towards a less aggressive production and consumption system.

\section{Conclusions}

This article identified and analyzed the extant literature concerning the opportunities and challenges the climate crisis presents to organizations, and how they respond to the situation (see Fig. 4). Additionally, the implications of big data management were presented (Section 4.3), in terms of how big data can enhance the opportunities or reduce the challenges faced by organizations in response to the current climate change crisis.

It identified the main opportunities created by the climate crisis, which include the following: improvement of environmental, financial and operational performance; improvement of relations with stakeholders; the generation of opportunities for new business. The main challenges can be categorised as: lack or inefficiency of governmental and regulatory support; stakeholder pressure in general; market pressure; the inherent characteristics of each organization; the quality and efficiency of actions and practices of low-carbon operations management; and cost increases.

Organizations respond to these opportunities and challenges through internal policy development, investment in research and development, voluntary adoption of low-carbon operations management practices, control and disclosure of the costs and benefits of climate change mitigation, and cooperation with other organizations.

Despite the knowledge identified and presented in this article, there are still many research gaps which future research can 


\begin{tabular}{|c|c|}
\hline Dimensions & Codes \\
\hline \multirow{4}{*}{ Context } & A - Developed countries \\
\hline & B - Developing countries \\
\hline & C-Developed and developing countries \\
\hline & D-Not applicable \\
\hline \multirow{9}{*}{ Continent } & A - North America \\
\hline & B - Central America \\
\hline & C - South America \\
\hline & $\mathrm{D}$ - Europe \\
\hline & E-Africa \\
\hline & $\mathrm{F}-$ Asia \\
\hline & $\mathrm{G}-$ Oceania \\
\hline & $\mathrm{H}$ - All continents \\
\hline & I- Not applicable \\
\hline \multirow{9}{*}{ Theoretical Base } & A - Institutional Theory \\
\hline & B - Stakeholders Theory \\
\hline & C-Contingency Theory \\
\hline & D-Resource-Based View \\
\hline & E-Not applicable/Not specified \\
\hline & F-Legitimacy Theory \\
\hline & G - Signaling Theory \\
\hline & $\mathrm{H}$ - Institutional Governance System Theory \\
\hline & I-Social Movements Theory \\
\hline \multirow{6}{*}{ Research Method } & A - Quantitative \\
\hline & B-Qualitative \\
\hline & C-Review \\
\hline & D - Conceptual \\
\hline & E - Case study \\
\hline & F-Survey \\
\hline \multirow{3}{*}{ Data origin } & A - Secondary Data \\
\hline & B-Empirical Research \\
\hline & C-Secondary Data and Empirical Research \\
\hline \multirow{4}{*}{ Analyzed Sector } & A-Manufacture \\
\hline & B-Services \\
\hline & C-Manufacture and Services \\
\hline & D-Not applicable/Not specified \\
\hline \multirow{7}{*}{ Focus } & A - Environmental performance \\
\hline & B - Operational and financial performance \\
\hline & C-Regulatory pressure \\
\hline & $\mathrm{D}$ - Stakeholder pressure \\
\hline & $\begin{array}{l}\text { E - Environmental management practices, strategies and investments (related to } \\
\text { managing low-carbon operations) }\end{array}$ \\
\hline & F-Climate change impact on business (opportunities and challenges) \\
\hline & G-Organizational characteristics (culture, department, size) \\
\hline \multirow{3}{*}{$\begin{array}{c}\text { Opportunities, } \\
\text { challenges and } \\
\text { organisational } \\
\text { behavior }\end{array}$} & A - Opportunities \\
\hline & B - Challenges \\
\hline & $\mathrm{C}$ - Organizational response \\
\hline
\end{tabular}

Chart 1. Dimensions and codes used to extract content from articles

address. For example, it would be interesting to investigate the challenges and opportunities presented by the climate crisis, and organizations' responses to these, in developing countries, especially in those Central America, Africa and South America. It would also be beneficial to investigate this subject through various theoretical lenses. Future research could employ a mixed methods approach in order to investigate how the opportunities and challenges of the climate crisis differ across manufacturing organizations and service sectors. It would also be of benefit to investigate how organizations develop the internal capabilities to deal with challenges presented by climate change, as well as the efficiency of low-carbon operations management practices adopted by organizations. New business opportunities which arise as a result of the climate crisis must also be studied, investigating whether the adoption of strategies, actions and practices to mitigate or adapt to climate change generate improvements in organizational operational performance. Likewise, an investigation of the relationships between the types of low-carbon practices adopted and organizations' inherent characteristics would further our understanding of the topic. Finally, future studies investigating the types of lowcarbon practices adopted by organizations as a result of cooperation with other organizations would be of great importance.

The evidence identified in the literature may serve as a guide to organizations that are involved in the climate crisis scenario and are unsure how to face the current challenges. It also demonstrates that this apparently threatening scenario can present great 
business opportunities, such as those derived from regulations and agreements. The Paris Agreement, for example, demands the injection of money from developed countries into poorer countries in order to mitigate climate change, a fact that can motivate and boost investment in research and development. For governments, this article may serve as a warning, because organizations need support, mainly in the form of efficient regulations, to cope with global warming, something relevant to each sector and every type of organization. In terms of the literature, this article presents a picture of the current knowledge on the topic, revealing that many issues are as yet unclear and require further explanation. The climate crisis is real and demands urgent solutions at all levels of society, and the operations management area can significantly contribute to these solutions. The research gaps identified will be able to serve as a guide to future researchers, enabling the evolution of the subject in the coming years.

Considering the results and discussions emerging from this article, it can be argued that big data is a key component to understanding the opportunities and challenges presented in Fig. 4.

However, this article also presented limitations: the searches conducted were restricted by the keyword combinations used, which may have limited the results; articles that emerged after the research was conducted were, obviously, not included in the analysis; and only the Scopus database was used to perform searches, which may have excluded articles from the analysis. Finally, the ways in which big data management can influence organizations' responses to the opportunities and challenges of climate change (Fig. 4) should be further investigated.

\section{Acknowledgements}

This work was partially supported by CAPES (Coordination for the Improvement of Higher Education Personnel), PDSE Processo $n^{\circ}$ $88881.133599 / 2016-01$

\section{References}

Agan, Y., Acar, M.F., Borodin, A., 2013. Drivers of environmental processes and their impact on performance: a study of Turkish SMEs. J. Clean. Prod. 51, 23-33. https://doi.org/10.1016/j.jclepro.2012.12.043.

Agarwal, R., Dhar, V., 2014. Big data, data science, and Analytics : the opportunity and challenge for IS research. Inf. Syst. Res. 25, 443-448.

Akhtar, P., Tse, Y.K., Khan, Z., Rao-Nicholson, R., 2016. Data-driven and adaptive leadership contributing to sustainability: global agri-food supply chains connected with emerging markets. Int. J. Prod. Econ. 181 (Part B), 392-401. https:// doi.org/10.1016/j.ijpe.2015.11.013.

Akter, S., Wamba, S.F., Gunasekaran, A., Dubey, R., Childe, S.J., 2016. How to improve firm performance using big data analytics capability and business strategy alignment? Int. J. Prod. Econ. 182, 113-131. https://doi.org/10.1016/ j.ijpe.2016.08.018.

Albornoz, F., Cole, M.A., Elliott, R.J.R., Ercolani, M.G., 2014. The environmental actions of firms: examining the role of spillovers, networks and absorptive capacity. J. Environ. Manag. 146, 150-163. https://doi.org/10.1016 j.jenvman.2014.07.011.

Belaud, J.-P., Negny, S., Dupros, F., Michéa, D., Vautrin, B., 2014. Collaborative simulation and scientific big data analysis: illustration for sustainability in natural hazards management and chemical process engineering. Comput. Ind. 65 (3), 521-535.

Berner, M., Graupner, E., Maedche, A., 2014. The information panopticon in the big data era. J. Organ Dysfunct. 3, 14. https://doi.org/10.7146/jod.9736.

Bicknell, S., Mcmanus, P., 2006. The canary in the coalmine: Australian ski resorts and their response to climate change. Geogr. Res. 44, 386-400. https://doi.org 10.1111/j.1745-5871.2006.00409.x.

Böttcher, C.F., Müller, M., 2015. Drivers, practices and outcomes of low-carbon operations: approaches of German automotive suppliers to cutting carbon emissions. Bus. Strat. Environ. 24, 477-498. https://doi.org/10.1002/bse.1832.

British Broadcasting Corporation, 2017. Paris climate Deal: Trump Pulls US Out of 2015 Accord (accessed in June 2017). http://www.bbc.com/news/world-uscanada-40127326/. Accessed 01.06.17.

Chen, C.L.P., Zhang, C.Y., 2014. Data-intensive applications, challenges, techniques and technologies: a survey on Big Data. Inf. Sci. (Ny) 275, 314-347. https:/ doi.org/10.1016/j.ins.2014.01.015.

Darnall, N., Edwards, D., 2006. Predicting the cost of environmental management system adoption: the role of capabilities, resources and ownership structure. Strat. Manag. J. 27, 301-320. https://doi.org/10.1002/smj.518.

Davenport, T.H., 2014. How strategists use "big data" to support internal business decisions, discovery and production. Strat. Leader. 42, 45-50. https://doi.org/ 10.1108/SL-05-2014-0034.

De Giovanni, P., 2012. Do internal and external environmental management contribute to the triple bottom line? Int. J. Oper. Prod. Manag. 32, 265-290. https://doi.org/10.1108/01443571211212574.

Demertzidis, N., Tsalis, T.A., Loupa, G., Nikolaou, I.E., 2015. A benchmarking framework to evaluate business climate change risks: a practical tool suitable for investors decision-making process. Clim. Risk Manag. 10, 95-105. https:// doi.org/10.1016/j.crm.2015.09.002.

Dragomir, V.D., 2012. The disclosure of industrial greenhouse gas emissions: a critical assessment of corporate sustainability reports. J. Clean. Prod. 29-30, 222-237. https://doi.org/10.1016/j.jclepro.2012.01.024.

Dubey, R., Gunasekaran, A., Papadopoulos, T., Childe, S.J., 2015. Green supply chain management enablers: mixed methods research. Sustain. Prod. Consum. 4, 72-88. https://doi.org/10.1016/j.spc.2015.07.001.

Dubey, R., Gunasekaran, A., Childe, S.J., Papadopoulos, T., Luo, Z., Wamba, S.F., Roubaud, D., 2017. Can big data and predictive analytics improve social and environmental sustainability? Technol. Forecast. Soc. Change 0-1. https:// doi.org/10.1016/j.techfore.2017.06.020.

El-Kassar, A.N., Singh, S.K., 2018. Green innovation and organizational performance: the influence of big data and the moderating role of management commitment and HR practices. Technol. Forecast. Soc. Change 1-16. https://doi.org/10.1016/ j.techfore.2017.12.016.

Environment Agency, 2015. Business Opportunities in a Changing Climate: Managing Impacts and Market Opportunities (accessed in June 2016). http://www. acclimatise.uk.com/login/uploaded/resources/EA\%20report.pdf/. Accessed 04.06.16.

Erevelles, S., Fukawa, N., Swayne, L., 2016. Big Data consumer analytics and the transformation of marketing. J. Bus. Res. 69, 897-904. https://doi.org/10.1016/ j.jbusres.2015.07.001

Feng, Q., George Shanthikumar, J., 2017. How research in production and operations management may evolve in the era of big data. Prod. Oper. Manag. 12, 3218-3221. https://doi.org/10.1111/poms.12836.

Fosso Wamba, S., Akter, S., Edwards, A., Chopin, G., Gnanzou, D., 2015. How "big data" can make big impact: findings from a systematic review and a longitudinal case study. Int. J. Prod. Econ. 165, 234-246. https://doi.org/10.1016/ j.ijpe.2014.12.031.

Gallego-Álvarez, I., Rodríguez-Domínguez, L., García-Sánchez, I.M., 2011. Study of some explanatory factors in the opportunities arising from climate change. J. Clean. Prod. 19, 912-926. https://doi.org/10.1016/j.jclepro.2011.02.012.

Gandomi, A., Haider, M., 2015. Beyond the hype: big data concepts, methods, and analytics. Int. J. Inf. Manag. 35, 137-144. https://doi.org/10.1016/ j.ijinfomgt.2014.10.007.

Gans, W., Hintermann, B., 2013. Market effects of voluntary climate action by firms: evidence from the chicago climate exchange. Environ. Resour. Econ. 55, 291-308. https://doi.org/10.1007/s10640-012-9626-7.

Gasbarro, F., Iraldo, F., Daddi, T., 2017. The drivers of multinational enterprises' climate change strategies: a quantitative study on climate-related risks and opportunities. J. Clean. Prod. 160, 8-26. https://doi.org/10.1016/ j.jclepro.2017.03.018.

Gaur, A., Kumar, M., 2018. A systematic approach to conducting review studies: an assessment of content analysis in 25years of IB research. J. World Bus. 53, 280-289. https://doi.org/10.1016/j.jwb.2017.11.003.

Glaser, B.G., Strauss, A.L., 2009. The Discovery of Grounded Theory: Strategies for Qualitative Research. Transaction Publishers.

Goes, P.B., 2014. Big data and IS research. MIS 0. 38, 3-8.

Griffiths, A., Haigh, N., Rassias, J., 2007. A framework for understanding institutional governance systems and climate change:. The Case of Australia. Eur. Manag. J. 25, 415-427. https://doi.org/10.1016/j.emj.2007.08.001.

Harmes, A., 2011. The limits of carbon disclosure: theorizing the business case for investor environmentalism. Global Environ. Polit. 11, 98-119. https://doi.org/ 10.1017/CBO9781107415324.004.

Intergovernmental Panel on Climate Change, 2007. Climate Change 2007: Working Group III: Mitigation of Climate Change (accessed in June 2016). http://www. ipcc.ch/publications_and_data/ar4/wg3/en/figure-ts-2.html/. Accessed 04.06.16.

Jabbour, C.J.C., 2013. Environmental training in organisations: from a literature review to a framework for future research. Resour. Conserv. Recycl. 74, 144-155. https://doi.org/10.1016/j.resconrec.2012.12.017.

Jabbour, C.J.C., Neto, A.S., Gobbo, J.A., Ribeiro, M.D.S., De Sousa Jabbour, A.B.L., 2015 Eco-innovations in more sustainable supply chains for a low-carbon economy: a multiple case study of human critical success factors in Brazilian leading companies. Int. J. Prod. Econ. 164, 245-257. https://doi.org/10.1016/ j.ijpe.2014.11.015.

Jarvis, N., Ortega, A.P., 2010. The impact of climate change on small hotels in the impact of climate change on small hotels in Granada, Spain. Tourism Hospit. Plann. Dev. 7, 283-299. https://doi.org/10.1080/1479053X.2010.502389.

Johnson, R.B., Onwuegbuzie, A.J., Turner, L.A., 2007. Toward a definition of mixed methods research. J. Mix. Methods Res. 1, 112-133. https://doi.org/10.1177/ 1558689806298224

Jones, C.A., Levy, D.L., 2007. North American business strategies towards climate change. Eur. Manag. J. 25, 428-440. https://doi.org/10.1016/j.emj.2007.07.001. 
Kolk, A., Levy, D., 2001. Winds of change: corporate strategy, climate change and oil multinationals. Eur. Manag. J. 19, 501-509. https://doi.org/10.1016/S02632373(01)00064-0.

Kuo, L., Huang, S.K., Wu, Y.-C.J., 2010. Operational efficiency integrating the evaluation of environmental investment: the case of Japan. Manag. Decis. 48, 1596-1616. https://doi.org/10.1108/00251741011090342.

Kuo, L., Yu, H.-C., Chang, B.-G., 2015. The signals of green governance on mitigation of climate change - evidence from Chinese firms. Int. J. Clim. Chang. Strateg. Manag. 7, 154-171. https://doi.org/10.1108/IJCCSM-07-2013-0083.

Lage Junior, M., Godinho Filho, M., 2010. Variations of the kanban system: literature review and classification. Int. J. Prod. Econ. 125, 13-21. https://doi.org/10.1016/ j.ijpe.2010.01.009.

Lee, K.-H., 2012. Carbon accounting for supply chain management in the automobile industry. J. Clean. Prod. 36, 83-93. https://doi.org/10.1016/j.jclepro.2012.02.023.

Lee, K.-H., Min, B., Yook, K.-H., 2015. The impacts of carbon (CO2) emissions and environmental research and development (R\&D) investment on firm performance. Int. J. Prod. Econ. 167, 1-11. https://doi.org/10.1016/j.ijpe.2015.05.018.

Liu, Y., 2012. An empirical research of awareness, behavior and barriers to enact carbon management of industrial firms in China. Sci. Total Environ. 425, 1-8. https://doi.org/10.1016/j.scitotenv.2012.02.077.

Lueg, R., Radlach, R., 2016. Managing sustainable development with management control systems: a literature review. Eur. Manag. J. 34, 158-171. https://doi.org/ 10.1016/j.emj.2015.11.005.

Mariano, E.B., Sobreiro, V.A., Rebelatto, D.A., do, N., 2015. Human development and data envelopment analysis: a structured literature review. Omega 54, 33-49. https://doi.org/10.1016/j.omega.2015.01.002.

Martin, R., Muûls, M., De Preux, L.B., Wagner, U.J., 2012. Anatomy of a paradox: management practices, organizational structure and energy efficiency. J. Environ. Econ. Manag. 63, 208-223. https://doi.org/10.1016/ j.jeem.2011.08.003.

Matthias, O., Fouweather, I., Gregory, I., Vernon, A., 2017. Making sense of Big Data can it transform operations management? Int. J. Oper. Prod. Manag. 37, $37-55$. https://doi.org/10.1108/IJOPM-02-2015-0084.

McAfee, A. Brynjolfsson, E., 2012. Big data: the management revolution. Harv. Bus. Rev. 90, 61-67, 00475394

McGuigan, C., Reynolds, R., Wiedmer, D., 2002. Poverty and climate change: assessing impacts in developing countries and the initiatives of the international community. London Sch. Econ. 1-40.

Misani, N., Pogutz, S., 2015. Unraveling the effects of environmental outcomes and processes on financial performance: a non-linear approach. Ecol. Econ. 109, 150-160. https://doi.org/10.1016/j.ecolecon.2014.11.010.

Nações Unidas no Brasil, 2016. Escassez de água pode limitar crescimento econômico nas próximas décadas. diz ONU (accessed in August 2016). https:// nacoesunidas.org/escassez-de-agua-pode-limitar-crescimento-economico-nasproximas-decadas-diz-onu/. Accessed 08.07.16.

Organisation for Economic Co-Operation and Development, 2015. Agriculture and Climate Change (accessed in July 2016). https://www.oecd.org/tad/sustainableagriculture/agriculture-climate-change-september-2015.pdf/. Accessed 08.07.16.

Pan, S., Ballot, E., Huang, G.Q., Montreuil, B., 2017. Physical Internet and interconnected logistics services: research and applications. Int. J. Prod. Res. 55 (9), 2603-2609. https://doi.org/10.1080/00207543.2017.1302620.

Philibert, C., 2004. International Energy Technology Collaboration and Climate Change Mitigation (accessed in June 2016). http://www.oecd.org/environment/ cc/32138947.pdf/. Accessed 04.06.16.

Popovič, A., Hackney, R., Tassabehji, R., Castelli, M., 2016. The impact of big data analytics on firms' high value business performance. Inf. Syst. Front 1-14. https://doi.org/10.1007/s10796-016-9720-4.

Raar, J., 2015. SMEs, environmental management and global warming: a fusion of influencing factors? J. Small Bus. Enterprise Dev. 22, 528-548. https://doi.org/ 10.1108/JSBED-10-2013-0157.

Rankin, M., Windsor, C., Wahyuni, D., 2011. An investigation of voluntary corporate greenhouse gas emissions reporting in a market governance system: Australian evidence. Account. Audit. Account. J. 24, 1037-1070. https://doi.org/10.1108/ 09513571111184751.

Rao, P., 2002. Greening the supply chain: a new initiative in South East Asia. Int. J. Oper. Prod. Manag. 22, 632-655. https://doi.org/10.1108/01443570210427668.

Reid, E.M., Toffel, M.W., 2009. Responding to public and private politics: corporate disclosure of climate change strategies. Strat. Manag. J. 30, 1157-1178. https:// doi.org/10.1002/smj.796.

Revell, A., Stokes, D., Chen, H., 2010. Small businesses and the environment: turning over a new leaf. Bus. Strat. Environ. 19, 273-288. https://doi.org/10.1002 bse.628.
Schaltegger, S., Csutora, M., 2012. Carbon accounting for sustainability and management. Status quo and challenges. J. Clean. Prod. 36, 1-16. https://doi.org 10.1016/j.jclepro.2012.06.024.

Schoenherr, T., Speier-Pero, C., 2015. Data science, predictive analytics, and big data in supply chain management: current state and future potential. J. Bus. Logist. 36, 120-132. https://doi.org/10.1111/jbl.12082.

Seuring, S., Gold, S., 2012. Conducting content-analysis based literature reviews in supply chain management. Supply Chain Manag. Int. J. 17 (5), 544-555. https:// doi.org/10.1108/13598541211258609.

Singh, Y., 2015. Environmental management through Green banking: a study of commercial banks in India. Int. J. Interdiscip. Multidiscip. Stud. 2, 17-26.

Song, M., Du, Q., Zhu, Q., 2017. A theoretical method of environmental performance evaluation in the context of big data. Prod. Plann. Contr. 28, 976-984. https:/ doi.org/10.1080/09537287.2017.1336801.

Sprengel, D.C., Busch, T., 2011. Stakeholder engagement and environmental strategy - the case of climate change. Bus. Strat. Environ. 364 https://doi.org/10.1002/ bse.684 n/a-n/a.

Sueyoshi, T., Goto, M., 2010. Measurement of a linkage among environmental, operational, and financial performance in Japanese manufacturing firms: a use of Data Envelopment Analysis with strong complementary slackness condition. Eur. J. Oper. Res. 207, 1742-1753. https://doi.org/10.1016/j.ejor.2010.07.024.

Sugita, M., Takahashi, T., 2015. Influence of corporate culture on environmenta management performance: an empirical study of Japanese firms. Corp. Soc. Responsib. Environ. Manag. 22, 182-192. https://doi.org/10.1002/csr.1346.

Takahashi, T., Nakamura, M., Kooten, G.C., van, Vertinsky, I., 2001. Rising to the Kyoto challenge: is the response of Canadian industry adequate? J. Environ. Manag. 63, 149-161. https://doi.org/10.1006/jema.2001.0467.

Tashakkori, A., Creswell, J.W., 2007. Editorial: the new era of mixed methods. J. Mix. Methods Res. 1, 3-7. https://doi.org/10.1177/2345678906293042.

The New York Times, 2017. Trump Will Withdraw U.S. From Paris Climate Agreement (accessed in June 2017). https://www.nytimes.com/2017/06/01/climate trump-paris-climate-agreement.html?_r=0/. Accessed 01.06.17.

Thomé, A.M.T., Scavarda, L.F., Scavarda, A., 2016. Conducting systematic literature review in operations management. Prod. Plann. Contr. 27 (5), 408-420. https:/ doi.org/10.1080/09537287.2015.1129464.

Tranfield, D., Denyer, D., Smart, P., 2003. Towards a methodology for developing evidence-informed management knowledge by means of systematic review. $\mathrm{Br}$. J. Manag. 14, 207-222. https://doi.org/10.1111/1467-8551.00375.

United Nations, 2015. Adoption of the Paris Agrément (accessed in June 2016) http://unfccc.int/resource/docs/2015/cop21/eng/109r01.pdf/. Accessed 23.06.16.

Wahyuni, D., Ratnatunga, J., 2015. Carbon strategies and management practices in an uncertain carbonomic environment - lessons learned from the coal-face. J. Clean. Prod. 96, 397-406. https://doi.org/10.1016/j.jclepro.2014.01.095.

Walenta, J., 2015. Becoming carbon Neutral : evaluating the carbon neutral certification as a tool for reducing climate change impacts and securing financial livelihoods. Sustain. J. Rec. 8, 121-126. https://doi.org/10.1089/ sus.2015.29002.jw.

Waller, M.A., Fawcett, S.E., 2013. Data science, predictive analytics, and big data: revolution that will transform supply chain design and management. J. Bus. Logist. 34, 77-84. https://doi.org/10.1111/jbl.12010.

Wang, G., Gunasekaran, A., Ngai, E.W.T., Papadopoulos, T., 2016. Big data analytics in logistics and supply chain management: certain investigations for research and applications. Int. J. Prod. Econ. 176, 98-110. https://doi.org/10.1016 j.ijpe.2016.03.014.

World Business Council for Sustainable Development, 2004. Running the Risk (accessed in June 2016). http://www.wbcsd.org/plugins/DocSearch/details.asp? type $=$ DocDet $\&$ DocID $=4660 /$. Accessed 28.06.16.

Wu, K.-J., Liao, C.-J., Tseng, M.-L., Lim, M.K., Hu, J., Tan, K., 2017. Toward sustainbility: using big data to explore the decisive attributes of supply chain risks and uncertainties. J. Clean. Prod. 142, 663-676.

Yu, Y., Wang, D.D., Li, S., Shi, Q., 2016. Assessment of U.S. firm-level climate change performance and strategy. Energy Pol. 92, 432-443. https://doi.org/10.1016/ j.enpol.2016.02.004

Zhang, Y., Ren, S., Liu, Y., Si, S., 2017. A big data analytics architecture for cleaner manufacturing and maintenance processes of complex products. J. Clean. Prod. 142, 626-641.

Zhu, Q., Sarkis, J., 2006. An inter-sectoral comparison of green supply chain management in China: drivers and practices. J. Clean. Prod. 14, 472-486. https:/ doi.org/10.1016/i.jclepro.2005.01.003.

Ziegler, A., Busch, T., Hoffmann, V.H., 2011. Disclosed corporate responses to climate change and stock performance: an international empirical analysis. Energy Econ. 33, 1283-1294. https://doi.org/10.1016/j.eneco.2011.03.007. 